Research/Technical Note

\title{
Evaluation of Sewerage System Sustainability Technically Around Condominiums Areas: A Case Study in Debre Berhan, Ethiopia
}

\author{
Fraol Abebe Wudineh", Nigatu Chala Kuke \\ Department of Civil Engineering, University of Debre Berhan, Debre Berhan, Ethiopia \\ Email address: \\ fraolabebe21@gmail.com (F. A. Wudineh),nigatuchala200@gmail.com (N. C. Kuke)
}

\section{To cite this article:}

Fraol Abebe Wudineh, Nigatu Chala Kuke. Evaluation of Sewerage System Sustainability Technically Around Condominiums Areas: A Case Study in Debre Berhan, Ethiopia. American Journal of Environmental Protection. Vol. 4, No. 6, 2015, pp. 318-324.

doi: 10.11648/j.ajep.20150406.18

\begin{abstract}
Sewage discharges from centralized water-borne collection systems can pollute surface water, and discharge from sewers; septic tanks and pit toilets pollute living environment and groundwater which directly affects the health of poor people at downstream [13]. Poor sanitation facilities and low sewerage system continues to be a critical problem in rural and urban areas of Ethiopia. This study aims to evaluate the sewerage system in terms of technical aspect by identifying the cause and extent of failures on the schemes then forwarding the mitigation measures for the problem explored. This study is conducted in Debre Berhan town from February, 2014-January, 2015. In order to gather information's for the study, the researchers used pre-prepared questionnaire (for the condominium lives), soil sampling and the other was data collection checklists (variable and context information checklists), semi open ended interview and physical instruments such as GPS, Axes soil sample bags. From the study, some important conclusions are made. The technical performance evaluation indicators show that sewerage system especially around condominium area is poorly implemented, inadequate in quantity, or poorly constructed or both. Of the total users around $31.54 \%$ have no any awareness about sewerage system operation, sanitation and hygiene. Of constructed floor drainage ditches only $24.8 \%$ have good appearance and functional, in the rest of scheme, the structure is destructed and non-functional. Only $36.47 \%$ of septic tanks, gives good function for users properly as required, in the rest of the schemes, there is many defects and problems observed. The technical problems noticed in the sample sites are includes O\&M, construction, and design respectively put in the order of causing considerable failure.
\end{abstract}

Keywords: Sustainable Sewerage, Water, Health, Hygiene, O\&M, Capacity Building, Grey Water Reuse

\section{Introduction}

Sanitation facilities with safe sewage disposal methods not only reduce the numerous diseases but are very often the first step towards to other development activities (MDGs).

Poor sanitation facilities and low sewerage system continues to be a critical problem in rural and urban areas of Ethiopia. Even if from a very low base, access to improved water and sanitation is raising rapidly the coverage of sanitation facilities is only $39 \%$ throughout the country up to 2010 compared with $48 \%$ for benchmark [1]. Lack of sufficient wastewater management in a community can face several risks on public health and the environment.
In addition to constructing new sanitary schemes, attention should be given to operation and maintenance of the existing schemes, in order to achieve the envisaged objectives. Substantial achievements will not be achieved unless the factors contributing to poor implementation of the old schemes are fully explored. Previous experiences should also be taken into account in the new schemes to avoid repetition of problems. Evaluation of impact is a longer-term activity. It is the process by which results of development projects are measured against their targets or objectives to see whether they have had the intended impacts or any undesired negative effects [20].

Debre Birhan is one of the town, which faced to problem of sewerage system management, especially around low cost 
houses found in this town. According 2014, D/Berhan town health office report, more than $82 \%$ of top ten diseases registered are directly connected to unsafe waste management around residential buildings[2].

This study aims to evaluate the sewerage system in terms of technical aspect by identifying the cause and extent of failures on the schemes then forwarding the mitigation measures for the problem explored.

\section{Materials and Methods of the Study}

\subsection{Study Area and Period}

This study is conducted in Debre Berhan town from February, 2014 - January, 2015. Debre berhan is one of fast growing towns found in Ethiopia located in north shewa zone, Amhara regional state, about $130 \mathrm{kms}$ north east of Addis Ababa on paved highway to Desse [10]. Debre Berhan town is determined by highland climatic zone with an avg. elevation of 2,840 meters and receives an annual rainfall of $920 \mathrm{~mm}$ while the temperature varies from 2.4 co in November to 23.3 co in June[11].

\subsection{Methods}

The paper commences with background information on the sewerage infrastructure status found in the condominium compound and the causes of damage to the infrastructure. In the second section the steps that were followed to determine functionality level for infrastructure are given. This is followed by a short discussion of the results obtained. Conclusions are given in the final section of the paper.

Data collection tools: In order to gather information's for the study, the researchers used pre-prepared questionnaire (for the condominium lives), soil sampling and the other was data collection checklists (variable and context information checklists), semi open ended interview and physical instruments such as GPS, Axes soil sample bags.

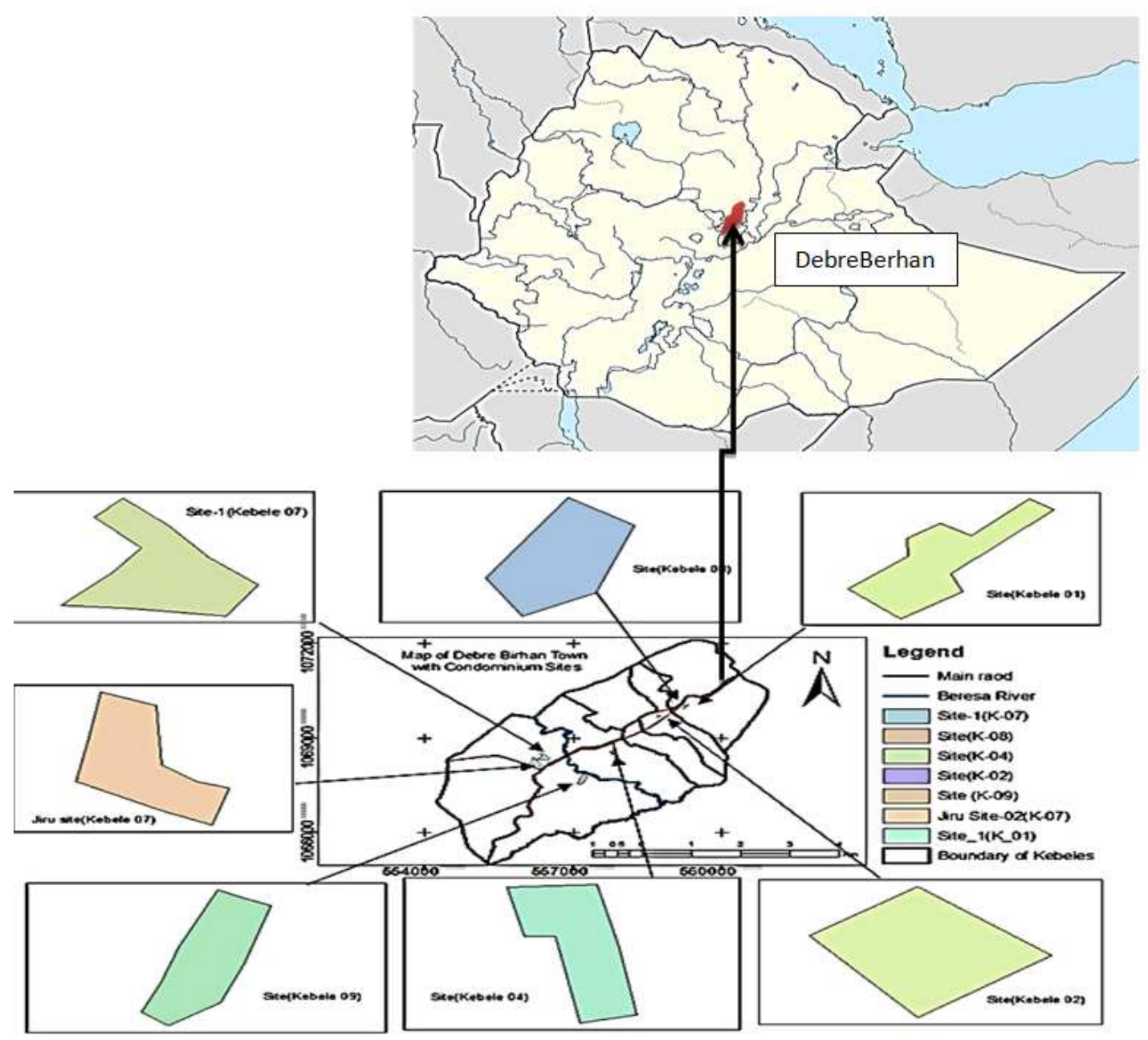

Figure 1. Map of study area.

\subsection{Sampling Methods and Data Collection}

Based on information about the problem on sewerage system, the study was carried out on all condominium sites found in the town which faced most visualized problems on sanitary system of town. The field data collection consisting of: interviews and data gathering from different stakeholders, field observation (on different infrastructures, sewerage system and other related schemes) and soil sample taken from each sites and tested at laboratory. 


\subsection{Methods of Data Analysis}

Both quantitative and qualitative methods of data analysis and interpretation were employed. Data obtained by questionnaires were analyzed using descriptive statics through percentage, mean and grand mean. In addition to this qualitative data gathering through observations, interviews were qualitatively analyzed. The data collected on the functionality and utilization of the sewerage system at local level of the seven study areas were analyzed for determination of the existing situation in the study areas. These findings on situations of the sewerage system at local level is analyzed and hence further suggestions and recommendations that will help to improve the sewerage system in the study areas was done.

\section{Results and Discussions}

\subsection{Household Characteristics}

Table 1. Household Characteristics $(N=76)$.

\begin{tabular}{ll}
\hline Variables & Frequency (percent) \\
\hline Sex of the respondents(N=76) & \\
Male & $43(56.58)$ \\
Female & $33(43.42)$ \\
Age group of the respondents $(\mathrm{N}=76)$ & \\
$<=35$ & $63(82.89)$ \\
$>35$ & $13(17.11)$ \\
Education status (N=76) & \\
Literate & $76(100)$ \\
Health and hygiene awareness level & \\
Un aware & $31.54 \%$ \\
Aware & $68.46 \%$ \\
\hline
\end{tabular}

$\mathrm{N}=$ Sample population

As indicated in Table 1, (56.58\%) of the respondents are male whereas $(43.42 \%)$ are females are participated on this study. Table 1 shows that $(82.89 \%)$ of respondents age are 35 and above whereas the left $(17.11 \%)$ are below 35 years. The result also shows that all respondents had literate. Also table shows that even if the literacy level of the family in study is good the awareness level on health and hygiene is different, that $(68.46 \%)$ of respondents have good awareness on health and hygiene whereas $(31.54 \%)$ of respondents have no sufficient awareness on health and hygiene which is the consequence of safe waste water disposal.

\subsection{Overview of the Sewerage Systems in the Study Areas}

Many of national regional and town's housing development projects have set ambitious goals of fulfilling residential houses and advanced waste disposal in past decade. In the study area the condominium sewerage systems are implemented by government and hand over to users, with cost recovery agreement. Inadequate delivery of condominium sewerage services, due to institutional constraints, user's way of services and fiscal difficulties is inhibiting the access of communities to basic sewerage system infrastructure services. Existing facilities are faced to different technical and institutional problems observed. According to discussions held with community and questionary result indicates that, in buildings the numbers of non-functional and non-operative fixtures are huge. Due to this the environment around the condominium sites are to some extent polluted, facing the living community to the health problem.

In Debre berhan town, the level of services ranges from internal sanitary system and external sewerage systems to septic tank with some subsurface disposal method. The septic tanks with subsurface soak away pits system serve few consumers and sites through condominium sewerage systems.

\subsection{Internal Sanitary System Physical Status, 2014}

Estimated 58 condominium buildings exist in the study town. These buildings internal sanitary systems are visited categorizing into seven sites. For the wastewater collection from each room upvc pipe is installed in all buildings. The system is single fixture pipe system. The diameter of each specific pipes are fixed based the flow quantity they collect according to Ethiopian Building Code Standards version 9, 1995 [8]. The diameter of waste water collector for internal sanitary system, in general, ranges from $50 \mathrm{~mm}$ to $110 \mathrm{~mm}$.

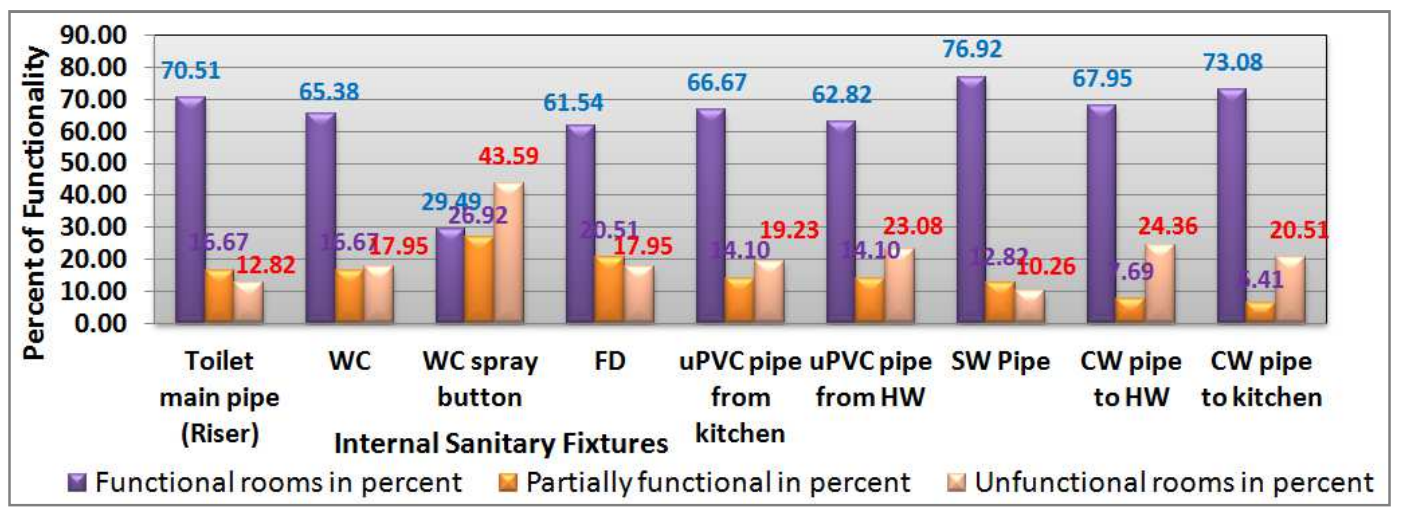

Figure 2. Functionality status of fixtures in internal sanitary system.

The physical status of fixtures installed in study buildings varies on different buildings as observed on figure 2 above. As can be seen on figure 2 among 58 toilet riser (truck pipe) only $41(70.51 \%)$ are functional; $9(16.67 \%)$ are partially functional 
and the rest $8(12.82 \%)$ are not functional as required. In the same manner the functionality status of all fixtures are indicated on figure 2 above in percent.

\subsection{External Sewerage System Physical Status, 2014}

There are 7 (seven) condominium sites exist in Debre berhan town. The external sewerage systems of the condominiums vary with size, topography of the sites, and typologies of the condominiums. External sewerage system of buildings composes storm line, underground buried sewers, and appurtenance structures such as man holes, septic tanks, launching aprons, filter Medias. For the wastewater collection from each room upvc pipe and concrete pipe is installed out of the buildings. The diameter of each specific pipes are fixed based the flow quantity they collect according to Ethiopian Building Code standard version 1995 Number nine [8]. The diameter of waste water collector for external sanitary system, in general, ranges from $110 \mathrm{~mm}$ to $200 \mathrm{~mm}$. The graph below shows that the physical status of schemes in percent.

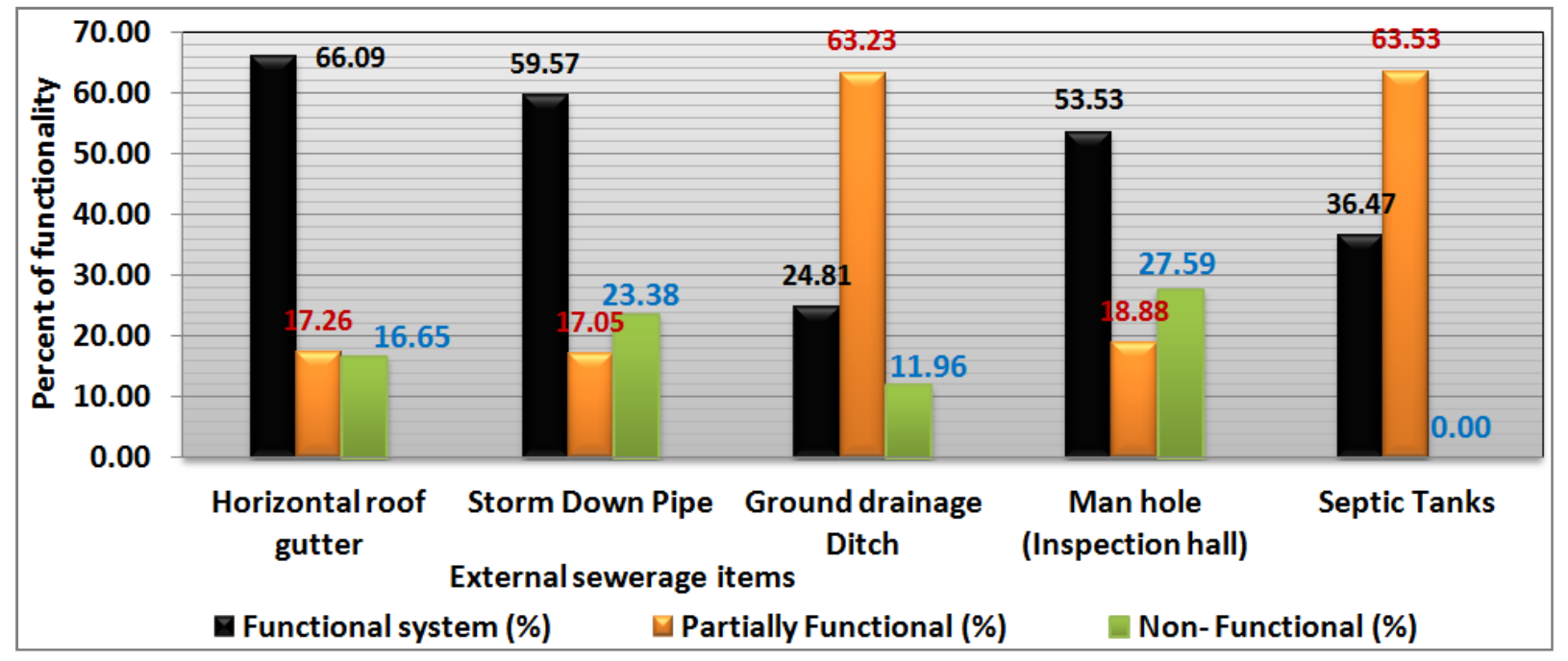

Figure 3. External Building sewerage scheme functionality status.

As indicated on graph above, around $74 \%$ of drainage ditch constructed around building could not give required function. This is the main cause observed for poor waste flow collection to dispose area. Around the area of buildings the numbers of surcharged sewers are high.

\section{Common and Major Problems on Sewerage Systems of Sample Sites}

Technical Problems: The significant technical problems noticed in the sample sites include operation and maintenance (O\&M), construction, and design respectively put in the order of causing considerable failure.

Institutional problems: Poor implementation of water and sanitation policies, lack of capacity to keep the system running after project completion and Lack of village level organization, like hygiene user association and water committee the main institutional problems investigated in the study area.

Social and Financial problems: Lack of awareness between users about benefits of improved sewerage system, absence of satisfaction between users with the service they get from sewerage facilities and less capability of users to generate efficient revenue for maintenance and operation (M\&O) purpose are the social and financial problems observed.

Environmental problem: Potential environmental problems included drainage problems around living apartments; pollution of living compound due to poor solid and liquid wastes and the sitting of latrines close to apartments; pounded wastewater around living areas as breeding grounds for mosquitoes and water borne and water related diseases.

\section{Major Causes for Sewerage System Failures of Sample Sites}

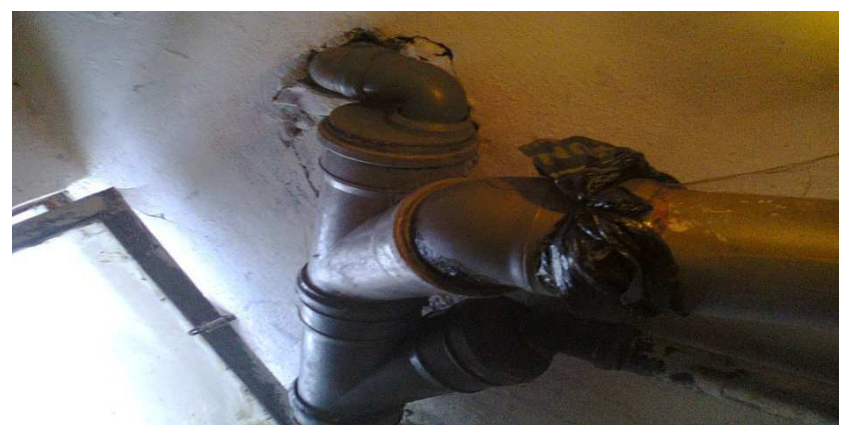

Figure 4. Leakage on main track (soil pipe).

Leakage of pipe at fittings: During construction/installation sewer lines and fittings on the sewer line are not appropriately installed. This implies that the two line which connect each other is not fitted correctly even by using any other fixture liquids such as solvent cement 500mg and fibers. 
Blockage during construction: Poor solid waste management is seen in the room and outside the room. This cause blockage of sewer line and floor drains which consequently cause surcharge of the flow on the floor.

Construction problem: miss of necessary construction item in building.

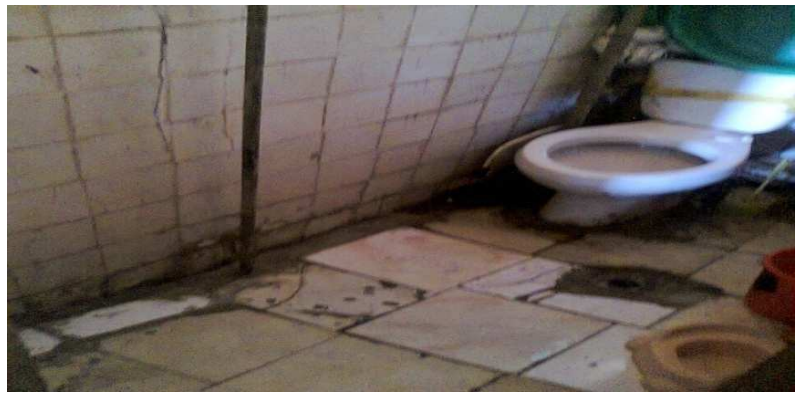

Figure 5. Missed shower tray from construction.

Design problem:

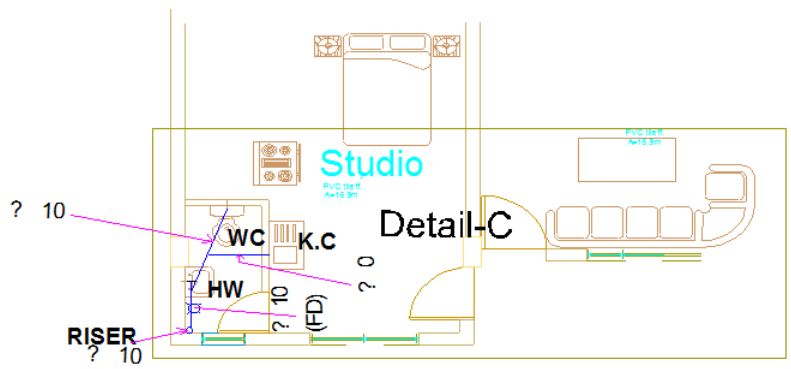

T3 waste water line layout

Figure 6. Deign problem observed on sanitary line layout.

The alignments of line and fixture sit are loosely planed, during design. The line of sanitary sewer takes large space in the room (for eg, in T3 typology, studio room, the line of sanitary sewer takes large space in the room).

Loosely tighten of gutter and down pipe: so that it releases rain water to wall.

Leakage of Septic tanks:

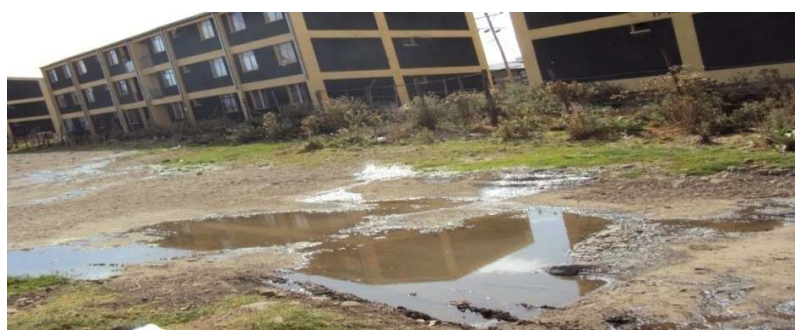

Figure 7. Leakage and over flow of sewage from septic tanks.

There is no periodical suck way implemented as per design, there is lateral inflow through the soil. Due to this, the flow from septic tank is simply leak to external road, side ditch without any secondary treatment which is the cause of health problem to communities. Eg Kebele 2 (site 3) and Kebele 7(melikt academy area).

Poor solid waste management
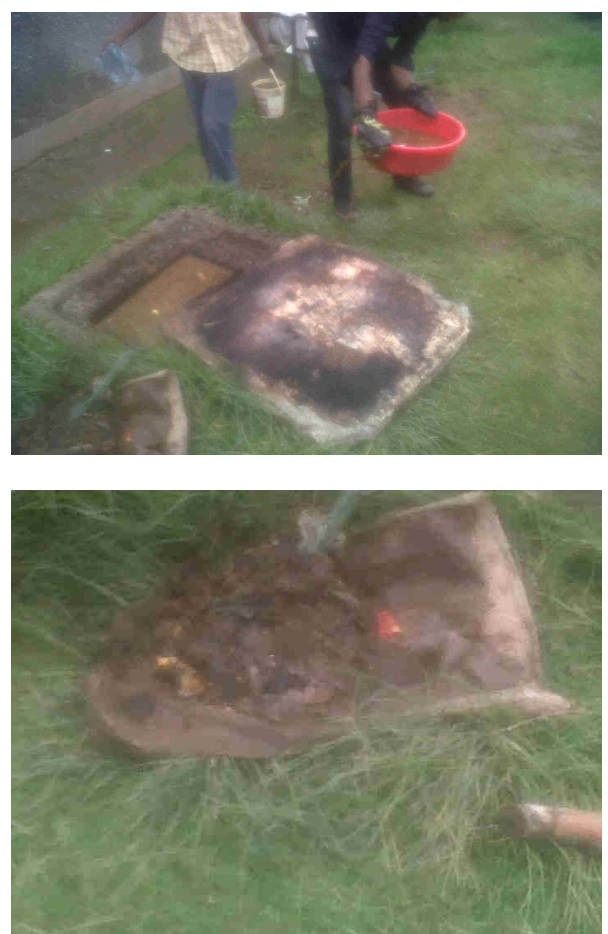

Figure 8. Community collects solid wastes from manholes manually which blocks sewers.

Solid wastes deposited on sewer line, in drainage ditches, manholes and septic tanks. Due this there is surcharge of wastes and over flow to the ground surface. In addition composite of solid waste around sewer, makes very difficult for sewer supervision.

Insufficient physical protection of floor drainage ditch, manholes and septic tanks:

Drainage ditches, manholes and septic tanks are totally buried under solid wastes (i.e., Stones, animal bones, and different garbage's) easily enter to the box and block the out let pipe frequently and fill manholes and block the flow line. Due this there is surcharge of wastes and over flow to the ground surface. In addition composite of solid waste around sewer, makes very difficult for sewer supervision.

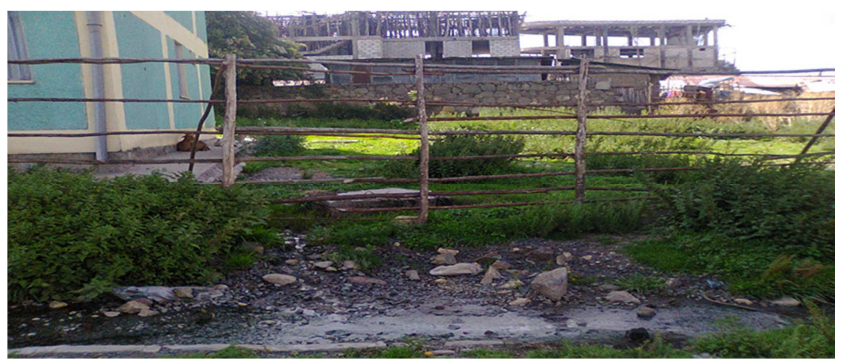

Figure 9. Overflow of sewage from manholes due to solid wastes filled in holes.

\section{Proposed Short and Long Term Strategically Remedies}

- The initial task has to be make awareness between the communities; how to use sanitary fixtures, way of 
dispose solid waste.

- A regular checking of the sewerage system, manhole cleaning and application of dilution are essential in order to ensure safety of community health.

- Giving maintenances for fixtures which leak flow and replacing fittings which show any rupturing and break.

- For those the sanitary alignment seen sever problem regarding space and material quality realignment is preferable based on the willingness and cooperation of households, who the line coincide their room.

- Community organizations responsible for the O\&M of sewerage system should be legally constituted and registered. The tariff collection should be regular, and tariff levels should be set according to the level of service and cover expenses for regular and periodic maintenance.

- Controlling infiltration using grouting or sealing of soils surrounding the sewer pipe, pipe relining, and sewer replacement, all of them are costly [14].

- Providing alternative sewage disposal methods;

Sand Filter Media and Soak away pits (based on soil percolation and topography of the area)[7].

According to laboratory result, soil type of Kebele 1,2,4 and 9(site1,site3,site4 and site7) show us sand and gravel which have greater percolation capacity than other types. So we can use such type disposal method in these a sites.

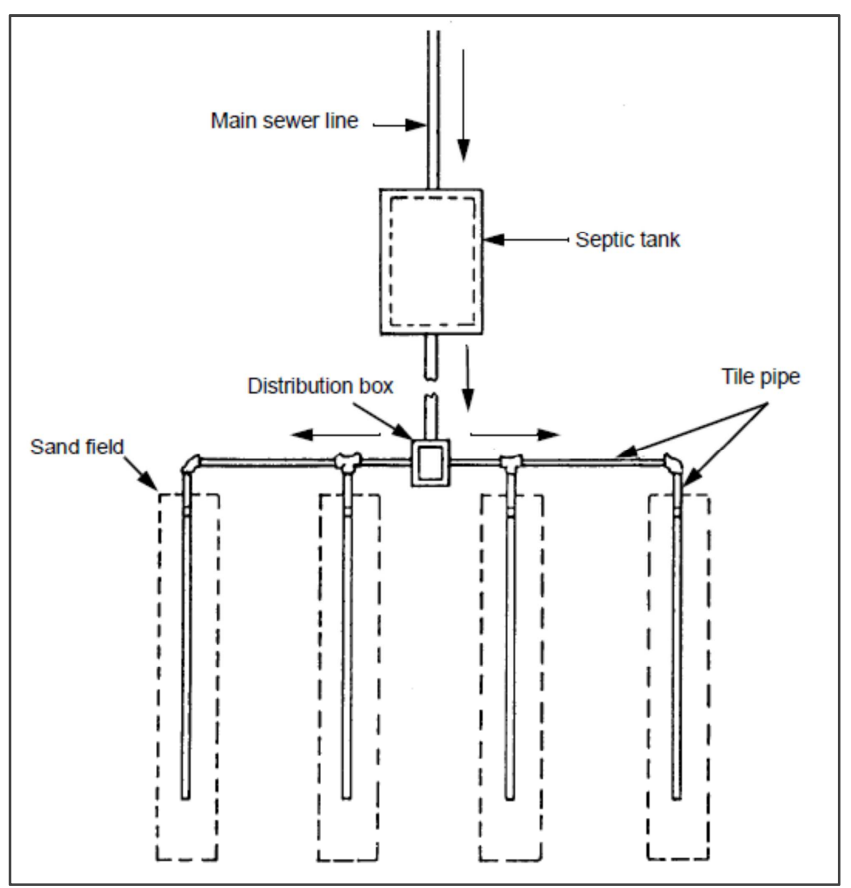

Figure 10. Sand Filter Media.

Vacuum Systems: 50 to $150 \mathrm{~mm}$ (2 to 6 inch) plastic pipe is buried deep in a vacuum, the source is connected to the vacuum through entry valve which opens automatically when a sufficient volume of sewage has accumulated and recloses when time interval reach to be drawn into the main. Then the vacuum is maintained by pumps at a central collecting tank [18].

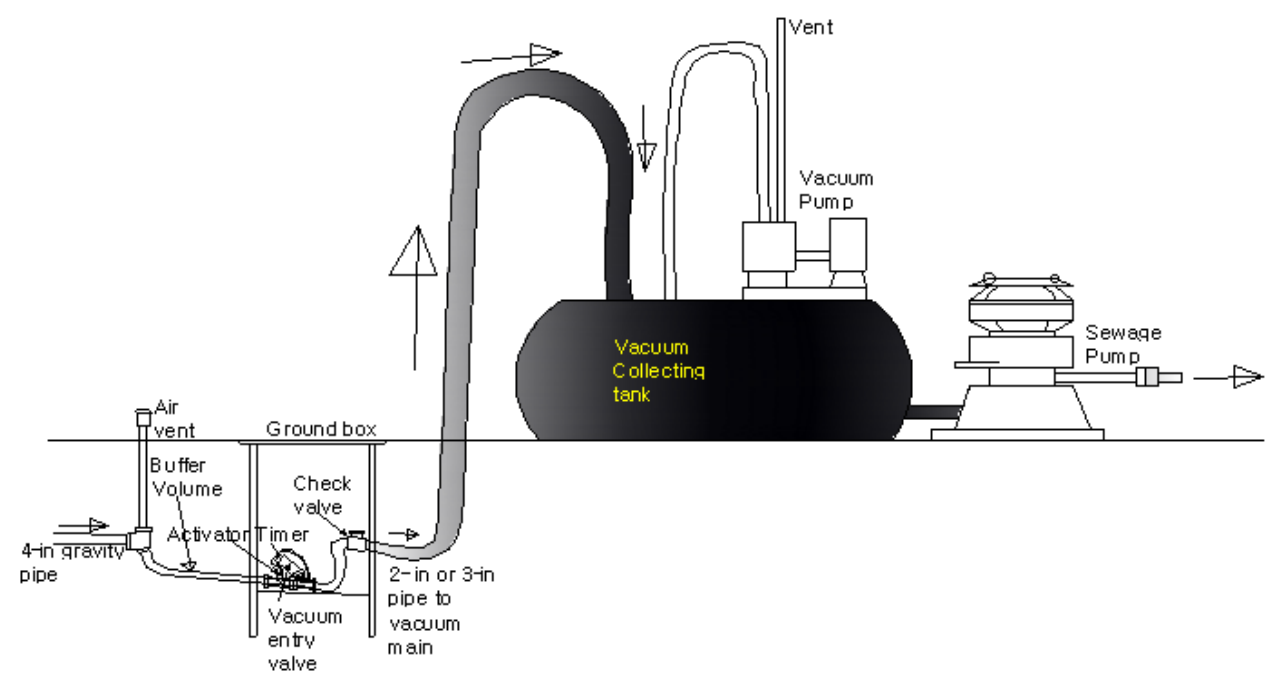

Figure 11. Vacuum system.

\section{Conclusions and Recommendations}

In the study area Projects were formulated through supply-driven approach and without consultation with representatives of communities. These factors have resulted in: absence in sense of ownership between communities and non-effective O\&M on the schemes.

To increase the level of ownership of future project, appropriate measures should be incorporated in the project design and implementation, such as capacity-building program for sector agencies and communities, and clear delineation of responsibilities among central, local agencies and communities.

From this study we noticed that O\&M is by far the weakest aspect at most of the sample projects. Poor administrative and technical supports, lack of operating fund are cited as the most 
frequent cause of failure.

Quality of construction is a crucially important parameter to be monitored in sewerage systems [6]. Though it looks that construction quality monitoring is neglected in the study areas. Construction materials checks and control (i.e. physical and chemical) before constructing the system, as well as on a regular basis should be considered in the future.

The other problems we have seen in the sample schemes are problems associated to the utilization and protection of the system and construction problem as a whole. Although technical sustainability depends largely on design and construction, it also depends on economic, social, political, cultural, financial, technological, and management aspects. Addressing these aspects calls for a well-designed, long-term, sewerage system monitoring and evaluation program complemented by all stakeholders.

Institutional weakness is the most significant problem in the study sites. Stated objectives are no set for the utilities. There is no NGOs take part on O\&M. Therefore we would like to forward that to undertake O\&M responsibility, integration of efforts under sanitation hygiene team composed of sectors like town water supply \& sewerage bureau, town health centers, NGOs and communities is required.

\section{References}

[1] Tessema, Yitbarek. 2013. Ethiopia - Ethiopia Water Supply and Sanitation Project: P076735 - Implementation Status Results Report: Sequence 19. Washington, D.C.: World Bank Group.

[2] Debre berhan town health Office (2014) Report of top Ten Diseases, Debre berhan, Ethiopia.

[3] 2012 Population and Housing Census of Ethiopia: Results for Amhara Region, Vol. 1, part 1, Tables 2.1, 2.7, 2.10, 2.13, 2.17, Annex II.2 [2012, April].

[4] A.P. Moser and Steven Folkman (2008) Buried Pipe Design (Third edition).

[5] Cairncross S, Carruthers I, Curtis D, Feachem R, Bradley D, Baldwin G (1980) Evaluation for village water supply planning,
John Wiley and Sons, New York.

[6] David Bufler and John W. Davis (2004), Urban Drainage (Second edition).

[7] Departments of the Army (August, 2001) Plumbing, Pipe Fitting, and Sewerage, Washington DC.

[8] EBCS-9 (1995) Ethiopian Building Code Standards Number Nine, Sectoral manual, Addis Ababa.

[9] Ethiopian News Agency [2009, May]"42-km Debrebirhan-Ankober road being maintained".

[10] http://www.en"Local History in Ethiopia" The Nordic Africa Institute website [2007, Dec.].

[11] http://www.enWikipedia.org/wiki/Debre_Berhan\#local_econo my.

[12] Jerrya. Nathanson(2009). Basic Environmental Technology Water supply, Waste Management, and Pollution control (Fifth edition), New Delhi_11001.

[13] Knut Werner Alsen, Petter D. Jansoon (2004) Ecological Sanitation (for mankind and nature), Norway.

[14] Mark. J. Hammer (2005) Water and Waste Water Technology (Fourth edition), New Delhi_11001, 2005.

[15] Metcalf \& Eddy, Inc. (1960). Wastewater Engineering-Treatment and Reuse (2nd edition). McGraw Hill. ISBN-13:978-0070418783.

[16] Pradnya Thakur and D.B. Panse (2012) Success Stories of Sustainable Sanitation Initiatives in India by ESF.

[17] S.K. Garg (March, 2008) Sewage Disposal and Air Pollution Engineering (21st edition).

[18] Terence J. McGHEE (1960) Water Supply and Sewerage (6th edition), McGRAW-HILL INTERNATIONAL EDITIONS.

[19] Unpublished document, March 2006 Adapted from Sanitary Fixtures Specifications, Avalon Pharma factory, Riyadh, Saudi Arabia.

[20] Selamawit Aseffa (2007) Evaluation of Technical sustainability of Rural water supply projects in the Amhara Regional state, case study in south Wollo, Addis Abeba, Ethiopia. 